\title{
Lignin as an Active Biomaterial: A Review
}

Nissa Nurfajrin Solihat ${ }^{1, *}$, Fahriya Puspita Sari ${ }^{1}$, Faizatul Falah ${ }^{1}$, Maya Ismayati ${ }^{1}$, Muhammad Adly Rahandi Lubis ${ }^{1}$, Widya Fatriasari ${ }^{1}$, Eko Budi Santoso ${ }^{2}$, Wasrin Syafii ${ }^{2}$

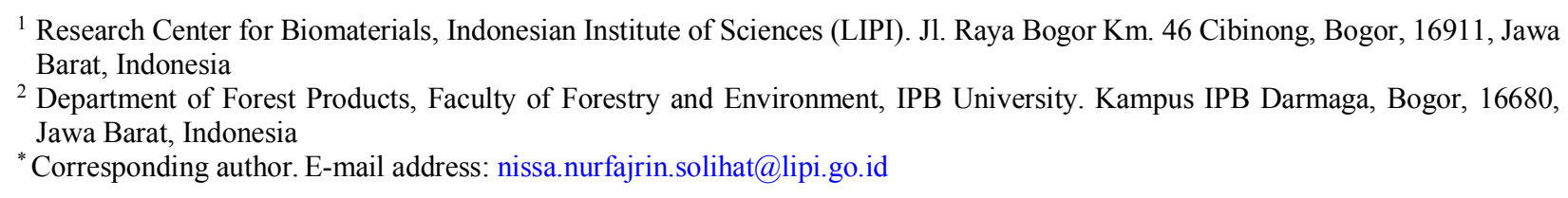

ARTICLE HISTORY:

Received: 14 October 2020

Peer review completed: 2 November 2020

Received in revised form: 24 November 2020

Accepted: 19 January 2021

\section{KEYWORDS:}

Active packaging

Antimicrobial agent

Bio-surfactant

Lignin

Supercapacitor

(C) 2021 The Author(s). Published by Department of Forestry, Faculty of Agriculture, University of Lampung in collaboration with Indonesia Network for Agroforestry Education (INAFE). This is an open access article under the CC BY-NC license:

https://creativecommons.org/licenses/by$\mathrm{nc} / 4.0 /$.

\begin{abstract}
Lignin is the second most naturally abundant biopolymer in the cell wall of lignocellulosic compound (15-35\%) after cellulose. Lignin can be generated in massive amounts as by-products in biorefineries and pulp and paper industries through differing processes. Most lignin is utilized as generating energy and has always been treated as waste. Due to the high amount of phenolic compounds in lignin, it is considered as a potential material for various polymers, building blocks, and biomaterials production. Even though lignin can be utilized in the form of isolated lignin directly, the modification of lignin can increase the wide range of lignin applications. Lignin-based copolymers and modified lignin show better miscibility with another polymeric matrix, outstanding to the enhanced performance of such lignin-based polymer composites. This article summarizes the properly updated information of lignin's potential applications, such as bio-surfactant, active packaging, antimicrobial agent, and supercapacitor.
\end{abstract}

\section{Introduction}

Environmental issues and lacking fossil fuels have been intriguing scientists to find biopolymer-based material in many applications (Thakur et al. 2014). The advantages of biopolymer include sustainable material, environmentally safe waste processing, and biodegradability. The polymer has been used in human applications, from household to aerospace. Global demand for the natural-based polymer is estimated in 2020 from 10.5 billion USD to 27.9 billion USD in 2025. This growth is mainly forced by the growing demand of various end-use industries such as packaging, agriculture, consumer goods, automotive, and transportation (MNM 2020). Therefore, the isolation of polymer from nature is futuristic to be applied in industry.

In nature, lignin is the second abundant biopolymer after cellulose in biomass. Lignin has a complicated cross-linked structure and is usually formed with ester linkage with hemicellulose. Lignin contains some active functional groups such as hydroxyl, methoxy, carbonyl, carboxyl, and benzene, where coniferyl alcohol $(\mathrm{G})$, p-coumaryl alcohol $(\mathrm{H})$, and sinapyl alcohol $(\mathrm{S})$ are precursors in lignin molecules (Fig. 1). 


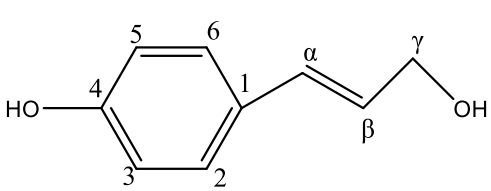

p-coumaryl alcohol

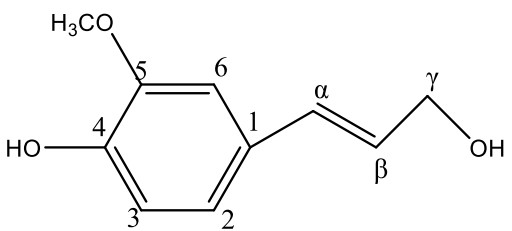

coniferyl alcohol

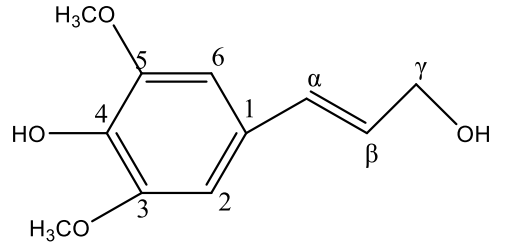

sinapyl alcohol

Fig. 1. Precursors of basic units in lignin (Chio et al. 2019).

More than $50 \%$ linkage in lignin is dominated by aryl ether linkage ( $\beta-\mathrm{O}-4$ '), which is the easiest linkage to be cleaved during lignin conversion and depolymerization. The others relevant linkage relatively more challenging to degrade are biphenyl $\left(5-5^{\prime}\right)$, resinol $(\beta-\beta)$, diphenyl ether (4-O-5'), phenylcoumaran $\left(\beta-5^{\prime}\right)$, and diphenylmethane $(\beta-1)$, the linkages are shown in Fig. 2 (Moreno and Sipponen 2020). The different sources of lignin, the different number of linkages, and precursors present in lignin. Lignin with abundant in $\mathrm{S}$ precursor is more recalcitrant and more stable in thermal due to the presence of two methoxyl groups (Nakagawa-Izumi et al. 2017). A previous study investigated the positive linearity of $\mathrm{S} / \mathrm{G}$ ratio and $\beta$-aryl ether content and lignin molecular weight, showing lignin with a high $\mathrm{S} / \mathrm{G}$ ratio was more susceptible to carbohydrate solubilization (Yoo et al. 2017). However, aromatic and hydroxyl group in all kinds of lignin play a critical role which is potentially converted into high-demand products such as bio-surfactant, microbial agent, active packaging, and supercapacitor.<smiles>COc1cc(C(O)C(CO)Oc2ccccc2OC)ccc1C</smiles><smiles>CCc1ccc2c(c1)OC(c1ccc(C)c(C)c1)C2CO</smiles><smiles>COc1cc(C2OCC3C(c4ccc(C(F)(F)F)cc4)OCC23)ccc1O</smiles><smiles>CCc1ccc(Oc2cc(OC(C)C)cc(OC)c2O)c(OC)c1</smiles>
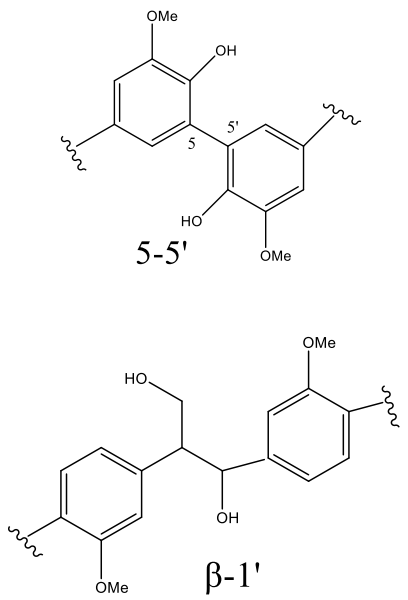

Fig. 2. Various linkages between precursors in lignin: $\beta-O-4$ '(aryl ether); $\beta-\beta$ '(resinol), $5-5$ ' (biphenyl), $\beta-5$ ' (phenylcoumaran), 4-O-5'(diphenyl ether) and $\beta-1$ ' (diphenylmethane) (Chan et al. 2013).

Surfactant is the most developed type of lignin-based chemical. However, chemical modification of lignin is needed to improve lignin's performance. For instance, major chemical modifications of lignin as a bio-surfactant are sulfonation, amination, methylation, and etherification (Huang et al. 2019). In addition, increasing health awareness increased the demand for antimicrobial products, estimated to reach USD 16 million in 2020 (Sriroth and Sunthornvarabhas 2018). The potential of lignin as an antimicrobial agent has been studied for decades, yet there are some critical roles such as lignin source, structure of lignin, type of bacteria, and concentration of lignin (Espinoza-Acosta et al. 2016). The demand for bio-polymer gained due to the high demand for natural based-packaging (MNM 2020). In the utilization of lignin as 
active packaging, the essential points are lignin's capability to be a radical scavenger and antioxidant agent. Finally, as the supercapacitor, some highlighted points are the activation through chemical and physical treatment to develop active pore of the lignin-derived activated carbon or supercapacitor. In a few years, several research articles to utilize lignin for those products have been published. However, its summary is still inadequate. Hence, the main focus of this article is to summarize the feasibility of lignin as indispensable material to prepare bio-surfactant, antimicrobial agent, active packaging, and supercapacitor.

\section{Lignin Sources}

Lignin can be classified as native and technical lignin. Native lignin is the original lignin structure in lignocellulose without any modification. While, technical lignin, known as modified lignin, is extracted from biomass or isolated from the industrial by-product. Typical technical lignin can be categorized as kraft lignin, hydrolysis lignin, organosolv lignin, and pyrolytic lignin (Chio et al. 2019). It can be directly used as raw material for the production of end-product due to the present active site of the aliphatic and aromatic hydroxyl group. Depolymerization is an important step to expose more reactive sites to convert lignin into further products.

Kraft process is the popular method that is applied in pulp and paper production. In this process, biomass is delignified by sodium hydroxide and sodium hydrosulfide liquor under various temperatures and cooking times. Kraft pulping of bagasse sorghum at $170^{\circ} \mathrm{C}$ for $2.5 \mathrm{~h}$ was effective in removing lignin and providing high cellulose content. After the treatment, the ether bond of cellulose and lignin cleavage and the biomass were washed to remove residual lignin in the pulp. This process was followed by obtaining black liquor as a by-product pulping process rich in lignin content (Fatriasari et al. 2015). Kraft lignin can be isolated by dropping acid into black liquor, and it will be precipitated in the bottom of the solution. The acidification process in isolation lignin from black liquor is effective in recovering ion sodium and sulfur in the solution that can be reused in further kraft pulping (Hermiati et al. 2017).

Bio-ethanol production is a promising application of biomass utilization. Cellulose and lignin are two major chemical components in biomass that had complex linkage. In bioethanol production, cellulose in biomass is a sugar monomer to convert into bioethanol during enzymatic hydrolysis, yet lignin cannot react with the enzyme and became hydrolysis lignin. The hydrolysis lignin contains lignin and other components such as untreated cellulose and oligosaccharides. Typically, hydrolysis lignin structure is similar to native lignin, and it has unique characteristics: low phenolic ratio and sulfur-free. However, it has a higher hydroxyl group content and thus results in higher reactivity compared to kraft lignin (Chio et al. 2019). Hydrolysis lignin is usually utilized as a biorefinery concept.

Organosolv lignin is sulfur-free lignin that was solubilized by organic solvent during the pulping process. Recent studies reported various organic solvents such as alcohol, acetic acid, organic acid, organic peracid, ketone, and ester to solubilize lignin in different biomass: corn, wheat, and pinewood (Chan et al. 2013; Zhang et al. 2016; Zhao et al. 2009). Compared to other extraction methods, the organosolv process obtained high lignin purity and remained a high cellulose residue. Consequently, it is considered ideal lignin to process lignin-based products.

Pyrolysis is a general method for lignin conversion to highly viscous bio-oil. After the pyrolysis step, water was added to the bio-oil and resulted in a fraction of water-insoluble. This fraction is known as pyrolytic lignin (PL). For the purification, PL was dissolved in an organic 
solvent to remove ash and other inorganic compounds. PL can usually be used as a natural resource for carbon fiber production (Chio et al. 2019).

\section{Potential Application of Lignin}

\subsection{Bio-Surfactant}

Surface active agents (surfactants) are chemicals that have two properties: hydrophilic head interacting with polar compound and hydrophobic tail interacting with a non-polar compound that commonly is produced from petroleum-based and chemically synthesized. Surfactants changed the interface's surface tension between two phases and usually act as emulsifier, dispersant, cosmetics, and detergent properties. Mostly it is used in agriculture, detergent industry, pesticide, food industry, oil mining for bioremediation, and healthcare (Fakruddin 2012). The global market of surfactant is expected to reach USD 1.85 billion by 2024 (Wood 2019). Due to the high demand for surfactant in the industrial area, researchers seek environmentally friendly and sustainable materials to produce surfactant due to lessening harmful environmental effects and depletion of petroleum, called bio-surfactant. It has some advantages compared to oil-based surfactants, such as easy to degrade in nature, sustainable material, low toxicity, reduced surface tension to $25 \mathrm{~m}$ $\mathrm{N} / \mathrm{M}$ on the water surface, biocompatible, and digestible in the industrial application (Fakruddin 2012). It was reported that oil-based chemicals in surfactant could be substituted with bio-based ones such as lignin (Norgren and Edlund 2014).

\subsubsection{Classification of lignin bio-surfactant}

As the second abundant polymer in lignocellulose material after cellulose, lignin application has been reviewed in many reports (Duval and Lawoko 2014; Norgren and Edlund 2014; Uraki et al. 2001). Classification of lignin-based bio-surfactants can be divided based on charge group in the molecule, such as cationic, anionic, amphoteric, and nonionic. Lignin cationic bio-surfactant is generally lignin amine and its derivatives where it was produced by the reaction of free hydrogen atoms in lignin with aldehyde and amine (Huang et al. 2019). The anionic surfactant is mainly produced through sulfonation as a result of substitution hydroxyl, hydrogen, and methoxy on the benzene ring or side chain as present in Fig. 3a (Zhang et al. 2017a). Amphoteric surfactant is a compound that has both charges positive and negative in one molecule. It can be obtained as a result of the expanding $\mathrm{pH}$ application range of lignin surfactant if sulfonic acid is reacted into the lignin amine. The negative charge is from the hydroxyl group and the positive charge from the amine group. The reaction process from lignin to amphoteric surfactant shows in Fig. 3b (Cai et al. 2017). On the contrary, nonionic surfactant does not have a charge in the molecule. Lignin nonionic surfactant does not contain either sulfonic or amino acid group, which cannot ionize in a polar solvent. Due to the milder properties of nonionic surfactant than other types of surfactant, it is generally used in beauty and personal care production. The synthesis route of nonionic surfactant shows in Fig. 3c (Qing et al. 2009). Type of reaction to synthesize four classes surfactant presents in Table 1. 
Table 1. Type of reaction to produce lignin bio-surfactant

\begin{tabular}{|c|c|c|}
\hline $\begin{array}{l}\text { Classification of lignin } \\
\text { bio-surfactant }\end{array}$ & Type of reaction & Reference \\
\hline Cationic & $\begin{array}{l}\text { Phenolation, Mannich reactions, ketone-amine } \\
\text { condensation }\end{array}$ & $\begin{array}{l}\text { (Liu et al. 2016; Liu et al. } \\
\text { 2013; Zhou et al. 2015) }\end{array}$ \\
\hline Anionic & $\begin{array}{l}\text { High-temperature sulfonation, } \\
\text { sulfomethylation, oxidation sulfonation, } \\
\text { oxidation nitration }\end{array}$ & $\begin{array}{l}\text { (Huang et al. 2018; Huang et } \\
\text { al. 2019; Konduri and Fatehi, } \\
\text { 2018) }\end{array}$ \\
\hline Amphoteric surfactant & Amination of lignosulfonate & $\begin{array}{l}\text { (Cai et al. 2017; Lou et al. } \\
\text { 2019; Tian et al. 2014) }\end{array}$ \\
\hline Nonionic surfactant & $\begin{array}{l}\text { Hydroxyl ammonium reaction, etherification, } \\
\text { epoxidation }\end{array}$ & $\begin{array}{l}\text { (Chen et al. 2016; Huang et al. } \\
\text { 2019) }\end{array}$ \\
\hline
\end{tabular}

a.

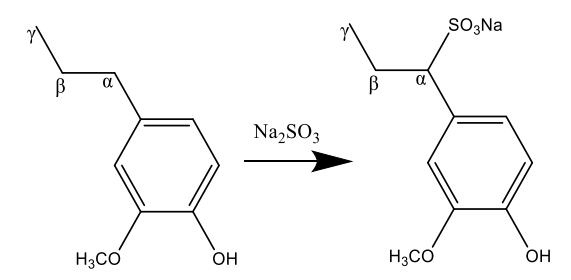

b.

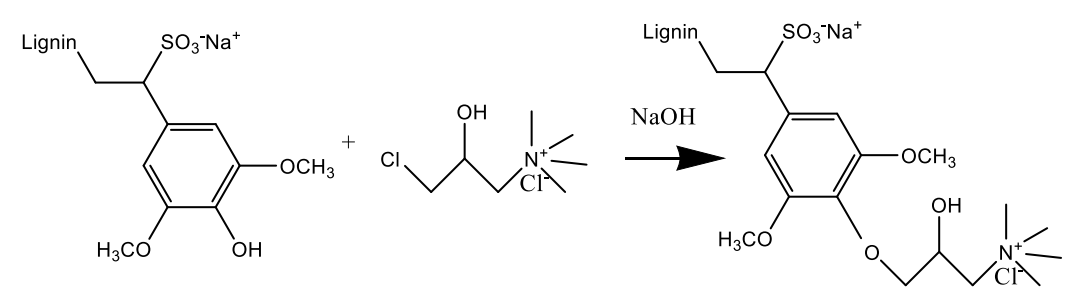

c.
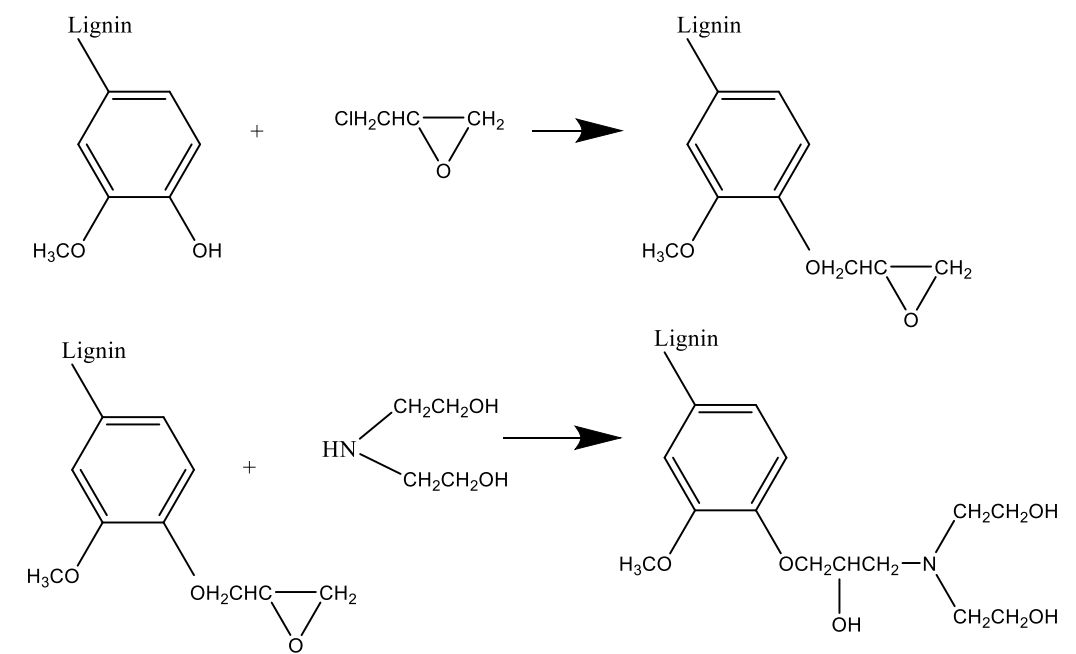

Fig. 3. Synthetic routes of (a) the sulfonation of lignin (Zhang et al. 2017b), (b) lignin amphoteric bio-surfactant (Cai et al. 2017), (c) diethanolamine-based lignin nonionic surfactant (Qing et al. 2009).

\subsubsection{Influencing factors of surfactant performance}

Some factors that affected surfactant performance are hydrophilic-lipophilic balance (HLB), the chain length, head group structure, and charge density. HLB is a common indicator in surfactant to measure partitioning tendency between oil and water. A surfactant with HLB between 4 and 6 can be used as water in an oil emulsifier, and HLB in the range of 8-18 is suitable to be used as oil in a water emulsifier (Kinyanjui et al. 2003). As the application, HLB ranged from 1.5 
- 3 usually applied as an antifoaming agent, $6-8$ as a wetting agent, $13-15$ as detergent, and 15 - 18 as solubilizer (Yamashita and Sakamoto 2016). The chemical structure of surfactant impacted HLB value, where adding more of the alkyl chain from 8 to 20 carbon atoms or number of lipophilic groups was reduced interface tension (Jiao et al. 2007). In addition, another researcher reported that the sulfonated surfactant with a long chain length (10-Acetoxy-9-hexoxy-2-sulfooctadecanoic acid methyl ester) reduced the interfacial tension of the core flood test (Mushtaq et al. 2014).

The type of surfactant head group is another impact factor in surfactant performance. Xu et al. (2013) reported four anionic surfactants with the same number of alkyl chain and different head group: sodium dodecyl sulfate (SDS), sodium dodecyl sulfonate (SDSn), sodium dodecyldi(oxyethylene) ether sulfate (AES), and sodium dodecylbenzene sulfonate (SDBS). AES was the highest capability to reduce interfacial tension due to the polarity of the head group. The order is as follows: AES > SDBS > SDS > SDSn. The polarity of surfactant was enhanced by the presence of oxygen, benzene ring, and oxyethyl group, which increased interaction between the head group and a water molecule ( $\mathrm{Xu}$ et al. 2013). On the other hand, increasing the charge density of surfactant could decrease media viscosity because of the increasing electrostatic repulsion between the surfactant and negatively charged functional group (Alwadani and Fatehi 2018).

\subsubsection{Chemical reaction to produce lignin-based bio-surfactant}

The complex structure of lignin is a challenge in synthesizing lignin-based bio-surfactant. Hence, scheme of converting reaction plays a substantial role in lignin conversion to value-added product. In the past years, many researchers studied the reaction of lignin conversion to biosurfactant to increase surface activity and feasible to be applied in industry. Lignin is usually mixed with polyethylene to produce bio-surfactant. For instance, blending kraft-lignin with polyethylene glycol diglycidyl ethers (PEDGE) successfully enhanced enzymatic hydrolysis for bioethanol production, and the reducing sugar yield increased about $20 \%$ besides of lignin-derivative biosurfactant (Fatriasari et al. 2018; Fatriasari et al. 2020). In another report, acetic lignin was reacted with PEDGE under atmospheric pressure, which reduced the amphiphilic viscosity to less than 0.3 dl/g and was effectively used as a cellulose stabilizer (Uraki et al., 2001). Polyethylene glycol and epoxy lignin were reacted with potassium persulfate as the catalyst to produce water-soluble alkali lignin. The analysis of emulsification and surface activity showed $43.30 \mathrm{nM} / \mathrm{m}$ at the critical micelle concentration. It was applied in the enzymatic hydrolysis of hardwood bleached pulp, and the result showed an increased glucose yield rate of as much as $18 \%$. Moreover, observation of the fermentation experiment showed that the product was not toxic for fermentation yeast (Chen et al. 2016). Cai et al. (2017) synthesized lignin amphoteric surfactant (SLQA) by reacting lignin lignosulfonate with (3-Chloro-2-hydroxypropyl)trimethylammonium Chloride (CHPTAC). The adding of SLQA in the enzymatic hydrolysis of pretreated eucalyptus and corncob elevated enzyme digestibility from $36 \%$ to 84 and $37 \%$ to $90 \%$, respectively. This method was reported significant in reducing the cost of bioethanol production (Cai et al. 2017). Another report stated that SLQA had no notable effect on recovering cellulase. Hence, adding dodecyl dimethyl betaine (BS12) in accordance with SLQA could improve the enzymatic hydrolysis of lignocellulose and recover cellulase (Lou et al. 2019). 
The reaction of lignin through the sulfite process is one popular reaction to produce lignosulfonate that have been applied as cement admixture, animal feed, oil well drilling, and pharmaceutical (Alwadani and Fatehi 2018; Aro and Fatehi 2017; Gargulak and Lebo 1999; Jiao et al. 2007; $\mathrm{Xu}$ and Ferdosian 2017). Alkaline lignin was reacted with sodium hydroxymethylsulfonate with a ratio in $\mathrm{mol} / \mathrm{mol} 0.1: 1.4$ at temperatures $110^{\circ} \mathrm{C}$ during reaction intervals (4h) and released $94.9 \%$ yield of lignosulfonate (AL-LG). Due to the low surface tension and zeta potential of AL-LG, its application on cement paste admixture showed effectiveness in improving the fluidity of cement paste regarding achieving a water-reducing ratio (Huang et al. 2018). Lignosulfonate has a function as binders and lubricants in animal feeds. Magnesium oxide $(\mathrm{MgO})$ as lubricant blended with lignosulfonate (LS) as a binder as an animal feed composition. The result indicating $\mathrm{MgO}+\mathrm{LS}$ was a more effective lubricant than vegetable oil (Winowiski and Zajakowski 2000). The lignosulfonate was grafted through copolymerization with acrylic compound and the resulted LS molecular with molecular weight 80,000. After adding acrylic acid, hydrogen peroxide was added into the sample and was heated for $3-4$ hours at $70-80^{\circ} \mathrm{C}$. The acrylic-lignosulfonate was effective as dispersant seawater drilling fluid (Kelley 1983). Moreover, grafting of acrylamide onto lignosulfonate with redox $\mathrm{H}_{2} \mathrm{O}_{2} / \mathrm{CaCl}_{2}$ and potassium persulfate at $30^{\circ} \mathrm{C}$ was successfully used in the salty water-based drilling fluids (Abdollahia et al. 2018). Ultrasound-assisted sulfonation process more effective than conventional heating, such as shorter time of reaction in lower temperature and higher yield of lignosulfonate (Ma'ruf et al. 2018). However, sulfonation reaction has some limitations, such as lower surface activity and the number of guaiacyl or free ortho positions in lignin was limited that condensed lignin and decreased sulfonation degree (Alwadani and Fatehi 2018; Zhang et al. 2017b).

Modification subsequent reaction of amination, sulfonation, and acetylation resulted in the higher surface activity of lignin compared to lignosulfonate. Firstly, amination was conducted by reacting purified lignin and diethylenetriamine, the aminated product (AL) was obtained after oven drying at $65^{\circ} \mathrm{C}$. Subsequently, AL reacted with sodium sulfite, and the $\mathrm{pH}$ was adjusted to 10 by adding $\mathrm{NaOH}$ solution with the temperature at $70^{\circ} \mathrm{C}$. Sulfonated product (SAL) was obtained after formaldehyde was dropped into the solution. Finally, SAL was reacted with palmitoyl chloride for $3.5 \mathrm{~h}$. The acylated product (ASAL) was obtained after oven drying at $65^{\circ} \mathrm{C}$. This reaction resulted in the interfacial tension reached to $5.0\left(10^{-3} \mathrm{~N} \cdot \mathrm{m}^{-1}\right)$, which indicated a suitable surfactant to enhance oil recovery compared to lignosulfonate (Zhang et al. 2017b). Anti-photolysis ligninbased dispersant for pesticide suspension concentrate was successfully synthesized through modification reaction of hindered amine (4-amino-2,2,6,6-tetramethylpiperidine) with sodium lignosulfonate, called SL-Temp. The obtained SL temp was used as a dispersant to prepare avermectin, and the result showed that the retention rate of avermectin was higher when it was added with SL-temp compared to adding lignosulfonate (Peng et al. 2020).

\subsection{Antimicrobial agent}

Lignin consists of many chemical functional groups, for example, methoxyl and phenolic hydroxyl group specifically the side-chain structure, which obtained various biological activities (Espinoza-Acosta et al. 2016). The phenolic fragments as the potency against microorganisms were granted by the existence of a double bond in the side chain ( $\alpha$ and $\beta)$ and the methyl group ( $\gamma$ position). Besides the chemical structure, type of bacteria used in the experiment, the sample 
origin, and antimicrobial dosage in the cultivation medium are also influenced factors of the efficacy of lignin as an antimicrobial agent (Kai et al. 2016).

Antimicrobial activities of lignin against bacteria, yeast, and fungi have been examined using guiacyl and syringyl model compounds. The result showed that microbial growth and enzymatic digestion were inhibited by the presence of phenolic monomers in lignin (Jung and Fahey 1983). The phenolic compounds damage and lysis cell membrane of bacteria (Cazacu et al. 2013). Lignin from various sources has been tested for antimicrobial activity against Gram-positive and Gramnegative at room temperature $\left(35^{\circ} \mathrm{C}\right)$ and low temperatures $\left(0-7^{\circ} \mathrm{C}\right)$. The results found that the antimicrobial activity depends on biomass source as follows: softwood organosolv $>$ softwood kraft $>$ grass organosolv due to the effect of acid-soluble lignin content. Inhibition zones of lignin samples from different sources were tested quantitatively against E. coli (as Gram-negative) and S. aureus, L. monocytogenes (as Gram-positive). Gram-negative bacteria were inhibited less than Gram-positive. The highest antimicrobial efficacy was obtained against $L$. monocytogenes, yet there was no activity studied lignin regarding E. coli (Alzagameem et al. 2019). A similar result was also shown for kraft lignin from black liquor (Klein et al. 2019) and lignin extract as the residue of converting corn stover to bioethanol, which exhibited antimicrobial activities against $L$. monocytogenes and $S$. aureus (Gram-positive) and C. lipolytica (yeast) but not for E. coli O157:H7 and S. Enteritidis (Gram-negative) or bacteriophage MS2 (Alzagameem et al. 2019; Dong et al. 2011). However, chitosan addition enhanced the activity of antimicrobial against Gram-positive and Gram-negative.

The concentration of antimicrobial in the cultivation medium was investigated and showed a critical effect. Kraft lignin as antimicrobial at low concentration $(0.25 \%$ on nutrition medium) was examined towards Erwinia carotovora and Xanthomonas vesicatoria and showed a positive effect. However, the inhibitory effect was not shown against Pseudomonas syringe and Bacillus polimyxa even at high concentration (2\%). On the other hand, Pseudomonas syringe presented inhibition effect at $2 \%$ concentration of spruce hydrolysis lignin (HL), yet only slight activity was observed at a concentration less than 2\% (Cazacu et al. 2013). Minet and colleagues reported antimicrobial testing good on knit fabrics with $2 \mathrm{wt} \%$ of kraft lignin toward E. Coli and $S$. epidermis (Minet et al. 2019). Extracted lignin from birch wood (1.06 mg DW) per $1 \mathrm{~mL}$ broth can inhibit the growth of $S$. aureus of $6.48 \mathrm{CFU} / \mathrm{mL}$ after incubation for $24 \mathrm{~h}$ at $37^{\circ} \mathrm{C}$ (Gabov et al. 2016). Isolated lignin was isolated at different $\mathrm{pH} 2-5$, and the antimicrobial activity was tested toward S. aureus and L. monocytogenes. The results showed that antimicrobial activity was increased as increasing $\mathrm{pH}$ of lignin and lignin concentration in the media (Klein et al. 2019).

Lignin as an antimicrobial agent is being used in commodity products like in plastic production (Klein et al. 2019), textile (Sriroth and Sunthornvarabhas 2018; Sunthornvarabhas et al. 2017; Sunthornvarabhas et al. 2018), medical materials, pest control, and healthcare products (Gordobil et al. 2018). Depletion of fossil fuels encouraged researchers to find sustainable material in plastic production. Klein et al. (2019) described demethylation of lignin as a reaction to produce lignin-polyurethane. Kraft lignin was acidic precipitated with different $\mathrm{pH} 2-5$ to evaluate the effect of extraction condition on antimicrobial activity in lignin-based polyurethane (LP). Subsequently, the obtained lignin in sodium hydroxide was demethylated by adding sodium sulfite and then was stirred for $1 \mathrm{~h}$ at room temperature. The process was stopped by dripping $1 \%$ of $\mathrm{HCl}$ to $\mathrm{pH} \mathrm{2}$, and the brown solid was precipitated as demethylated lignin. Unmodified (KL) and demethylated lignin (DL) were used to prepare lignin-based polyurethane. S. aureus was used as an antimicrobial organism with an inoculation temperature of $37^{\circ} \mathrm{C}$ for $24 \mathrm{~h}$. A significant 
microbial reduction toward $S$. aureus was observed as increasing $\mathrm{pH}$ of DL than other samples. Demethylation reaction can improve the cross-linking density of the LP and correlated with its antimicrobial activity (Klein et al. 2019).

Hydroxypropylmethylcellulose-lignin (HPMC-lignin) and HPMC-lignin-chitosan were studied to evaluate lignin as antimicrobial in film. Lignin powder isolated from black liquor was diluted in DMSO. Next, the film of HPMC-lignin was formed by stirring HPMC and lignin solution for $15 \mathrm{~min}$. Besides, HPMC-lignin-chitosan was prepared by adding deacetylated chitosan in ethanol. The antimicrobial activity of both films was analyzed toward $S$. aureus and E. coli in saline solution for $24 \mathrm{~h}$ at $35^{\circ} \mathrm{C}$. The HMPC-lignin film had an active antimicrobial test toward $S$. aureus but not for E. coli. Conversely, microbial activity toward both $S$. aureus and $E$. coli was positive after chitosan addition (HMPC-lignin-chitosan). Lignin concentration in the film was also a critical effect on antimicrobial activity where the activity increased as increasing active functional group such as aliphatic $\mathrm{OH}$, carbonyl $\mathrm{CO}$, and $\mathrm{COOH}$. Antimicrobial activity toward $E$. coli in the film only was observed after $30 \%$ addition of lignin concentration, while activity against $S$. aureus was observed in addition of lignin 5\%. However, chitosan in HPMC/lignin film improved the activity where the concentration of lignin 5\% had antimicrobial activity against $E$. coli. Chitosan consists of amino and hydroxyl group in its structure, which is known as an antimicrobial compound toward Gram-positive and Gram-negative bacteria. Furthermore, the activity was also tested against $B$. thermosphacta and $P$. fluorescen bacteria. Both HMPC-lignin and HMPC-lignin-chitosan showed activity only at lignin concentration of $30 \%$ against $B$. thermosphacta and 5\% against $P$. fluorescen. Higher resistance of $P$. fluorescen than $E$. coli was observed due to exopolysaccharides production (Alzagameem et al. 2019). Another film of mixing lignin with PVA/gelatin blends exert highly antibacterial activity, especially against foodborne contaminants such as Escherichia coli, Bacillus subtilis, Staphylococcus aureus, Pseudomonas aeruginosa. Hydroxyl group of lignin as a phenolic compound interacted with the bacterial cell causing cell membrane disruption, the infiltration of cell components, and ultimately bacterial cell lysis (El-Nemr et al. 2019). Yang et al. (2016a) also reported that polymeric film-based PVA, chitosan, and lignin nanoparticle could inhibit the bacterial growth of Erwinia carotovora subsp. carotovora and Xanthomonas arboricola pv. pruni. From those experiments, lignin could be considered as a promising antimicrobial agent for food packaging. The main effect of antimicrobial activity in active packaging is controlling spoilage of microbial and pathogen contamination onto food by inhibiting microbial growth, include inhibit topoisomerase, NADH-cytochrome c reductase, and ATP synthase, also damage the cytoplasmic membrane (Diblan and Kaya 2017; Rempe et al. 2017). Further explanation of lignin as food packaging is available in the active packaging section.

The demand for antimicrobial textile in medical and non-medical rapidly increased where the coating of antimicrobial agents on the fiber is a simple method. In 2017, Sunthornvarabhas et al. (2017) coated lignin from sugarcane bagasse on fabric to produce antimicrobial textile. Lignin was dissolved in DMSO and subsequently was mixed with ethyl alcohol. The solution was submerged with glass fiber then placed in an oven at $60^{\circ} \mathrm{C}$ for $2 \mathrm{~h}$ before sterilization under UV light. The antimicrobial activity of coated-fiber was tested against Staphylococcus epidermidis, the most bacterial found in human skin. Concentration minimum of bactericidal (MBC) and inhibitory (MIC) of lignin were tested by broth dilution method. The result presented that increasing extract amount of lignin decreased in colony formation, which means more activity of antimicrobial properties (Sunthornvarabhas et al. 2017). Bamboo fiber has been popular in recent 
years in the fashion industry as eco-friendly and antibacterial textile. The antimicrobial activities in bamboo clothing were investigated against Gram-negative bacterium, Escherichia coli, and the extract dissolved in dioxane showed strong activities due to the presence of lignin (Afrin et al. 2012). The illustration of antimicrobial textile is shown in Fig. 4.

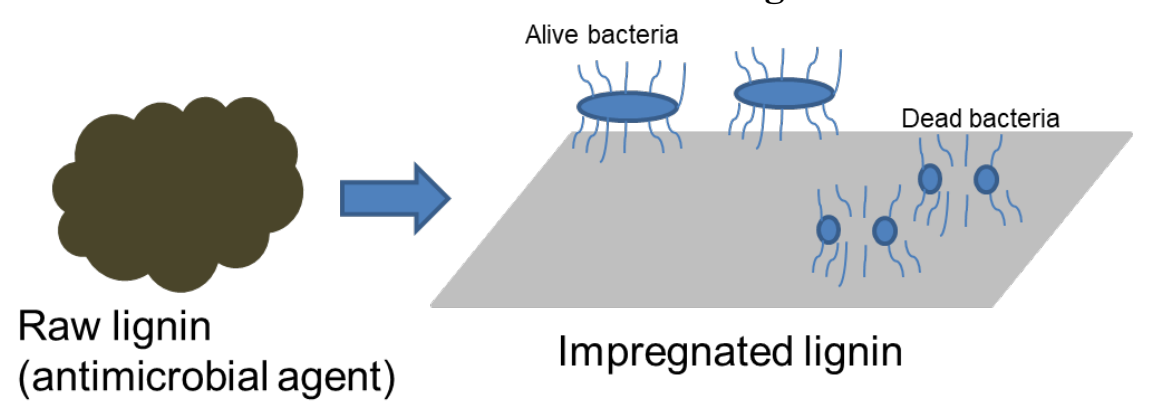

Fig. 4. Schematic of antimicrobial textile (Riaz and Ashraf 2020; Zhu et al. 2019).

In Thailand, natural antimicrobial extract generously gains attention in the application of medical and cosmetic. It was predicted that antimicrobial product demand reached USD 16 million in 2020 (Sriroth and Sunthornvarabhas 2018). Lignin in healthcare products such as cosmetics plays a role not only as an antimicrobial agent but also as an antioxidant and sun protection factor (SPF). Recently, Gordobil et al. (2018) evaluated the potency of kraft and organosolv lignin for healthcare products through measurements of antibacterial activity, antioxidant capacity, and SPF. Lignin showed similar functional properties as a commercial antioxidant, which suitable for use in cosmetics, replacing butylated hydroxyanisole (BHA) or butylated hydroxytoluene (BHT), which is cytotoxic synthetic antioxidants. In addition, antimicrobial activity towards $\mathrm{A}$. niger, diverse foodborne, and human pathogenic showed positive inhibition that opened new insight to be used in food and pharmaceutical products. SPF determination of lignin-based sunscreen was conducted by in vitro method. The lignin concentration in the product significantly affected SPF result due to the transmittance of elaborated creams was decreased by higher lignin content. Moreover, the higher content of methoxyl and carbonyl group improved exposure of ultraviolet due to the auxochromes. Therefore, it concluded the potency of lignin to eliminate harmful commercial chemicals in sunscreen products (Gordobil et al. 2018).

Copper (II) sulphate is commonly used in pesticides. However, the environmental issue is intriguing researchers to find sustainable raw material for reducing copper content. Due to highly polar and easily washed off of Copper (II) sulphate, it gave serious environmental problems. In 2018, Sinisi et al. (2018) reported a novel product of combining $\mathrm{Cu}$-lignin as antibacterial and antifungal for pesticide products. Lignin from Pinus taeda was dissolved in water and added $\mathrm{CuSO}_{4}, \mathrm{NaOH}$ was added until $\mathrm{pH}$ 7, and the precipitate brown solid was filtered and dried for further analysis. The ratio of lignin $/ \mathrm{CuSO}_{4}$ was conducted to find the best condition of pesticide. The antimicrobial activity was tested against yeast and several microorganisms: Escherichia coli, Pseudomonas aeruginosa, Staphylococcus aureus, Salmonella enteridis, Erwinia amylorova, Pseudomonas syringae pv actinidiae, Xanthomonas campestris, Campylobacter jejuni, and Xanthomonas arboricola pv pruni. In general, $\mathrm{Cu}$-lignin gave good activity towards Gram-positive and Gram-negative, which potential to be used as an antibacterial agent (Sinisi et al. 2018). 


\subsection{Active packaging}

The market for food packaging exhibits constant growth. The utilization of renewable biopolymers aims to reduce the amount of non-renewable raw material. Using lignin as new materials to substitute certain synthetic and petroleum-based materials in the use of bio-polymers has increased. Lignin structure contains functional groups that have aromatic and highly crosslinked structure. Therefore, lignin can be compatible with many polymeric matrixes to increase mechanical properties, fire resistance, and wettability. It has been reported that lignin is effectivity as food packaging additives (Alzagameem et al. 2019) and a filler in active packaging depends on polymer matrices, like polyvinyl alcohol (El-Nemr et al. 2019; Yang et al. 2016b), latex (Johansson et al. 2012, 2014) and PLA (Chaubey et al. 2020; Gordobil et al. 2014; Spiridon et al. 2015; Yang et al. 2016a; Yang et al. 2020), chitosan (Crouvisier-Urion et al. 2019; Yang et al. 2016a), gelatin (Aadil et al. 2016a; El-Nemr et al. 2019), alginate (Aadil et al. 2016b) based materials.

Lignin has potential as a natural antioxidant additive in food packaging due to its polyphenolic structure (Domenek et al. 2013; Faustino et al. 2010; Vinardell et al. 2008; Vostrejs et al. 2020; Yang et al. 2020; Zadeh et al. 2019). The lignin with narrow polydispersity, low molecular weight, more phenolic hydroxyl groups, and less aliphatic hydroxyl groups showed high antioxidant activity (Pan et al. 2006). Adding lignin in packaging improves the antioxidant properties of food and antimicrobial properties (El-Nemr et al. 2019; Li and Peng 2015; Yang et al. 2016a; Yang et al. 2016b). Natural antioxidants could also be used in active packaging to protect food that has a sensitivity to light and oxygen. Antioxidant agents such as lignin can be applied to food packaging by various methods. These agents can migrate to the protected food through the inner walls of the packaging material. Fig. 5 illustrates the scheme and migration process in each system.

Several studies have been conducted to compare extracted lignin from different sources such as alkali (Aadil et al. 2016a), lignosulfonate (Li and Peng, 2015), kraft (Faustino et al. 2010), or steam explosion lignin (Vinardell et al. 2008). Lignosulfonate and alkali lignin were used in soy protein isolate (SPI) bio-polymeric film modified enzymatically. The radical scavenging activity test of the films containing lignosulfonate $6 \%$ higher than alkali lignin-based film and had values of 28, but if only alkali lignin itself had much higher radical scavenging activity than lignosulfonate (Zadeh et al. 2018). Alkali lignin has higher radical scavenging activity than the other lignin because it contained free phenolic monomers, particularly p-coumaric and ferulic acids (Domenek et al. 2013). Alkali lignin in modified film reduced the oxidation rate to $75 \%$ in the ability of UV blocking and the activity of radical scavenging (Zadeh et al. 2018). Lignin phenolic substructures are contributed to antioxidant activity, and UV-blocking property from low to high was p-hydroxyphenyl phenolic hydroxyl groups $>$ guaiacyl $>$ syringyl. Syringyl phenolic units have the highest antioxidant activities and UV-shielding properties because it contains additional methoxyl groups (Guo et al. 2019).

Lignin isolated from grape seeds was used as an additive material for radical scavenging in active packaging. Grape seed lignin is effective as an antioxidant agent with a high antioxidant capacity ( $1 \mathrm{~g}$ of grape seeds lignin equal to $238 \mathrm{mg}$ of Trolox). The lignin was added to the poly (3-hydroxybutyrate) (PHB) and polyhydroxyalkanoate (PHA) film. It acted not only as an antioxidant but also as a nucleating agent. Moreover, it increased the stiffness and degree of crystallinity of the film and contributed to the lower oxygen and carbon dioxide permeability of 
the film (Vostrejs et al. 2020). The antioxidant activity of lignin monomers has significant differences regarding their initial radical scavenging activity. Coumaric, ferulic, and sinapic acids as phenolic acids that compose lignin were investigated for their radical activity. Sinapic acid has the highest radical activity due to di-ortho-methoxyl substitution, ferulic acid has an intermediate activity, and coumaric acid has no antioxidant activity. The results could confirm that the higher concentration of syringyl, the higher the antioxidant activity (Crouvisier-Urion et al. 2019). Biopolymer matrix from Poly(lactide) (PLA)-lignin results in a good dispersion. The compounded material slightly enhanced the oxygen barrier properties. The physical and mechanical properties of PLA film with the addition of lignin also showed improvement (Aadil et al. 2016a; Domenek et al. 2013). The experiment was also found that the formation of free phenolic monomers will increase antioxidant activity. Antioxidant activities increase along with the increasing severity of the heat treatment. The antioxidant of lignin was not only potential for active packaging but also for cosmetic formulation because lignin was considered as non-irritants to the eye and skin (Vinardell et al. 2008). Another research reported that HPMC-lignin and HPMC-lignin-chitosan films were studied to evaluate the application of lignin for food packaging additives. The result showed it has good antioxidant activity and antimicrobial activity (Alzagameem et al. 2019). In addition, filler of blending of lignin with PVA/gelatin showed good result as active packaging to inhibit microbes (Yang et al. 2016a). The explanation of antimicrobial activity is described in the antimicrobial section.

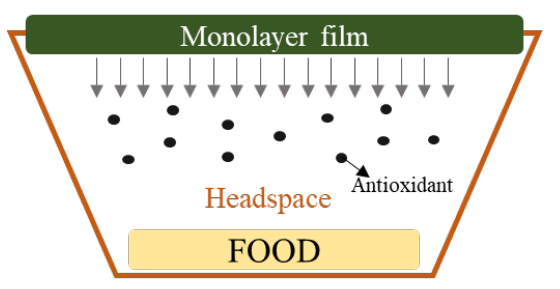

a). Antioxidant release directly from active packaging into the food

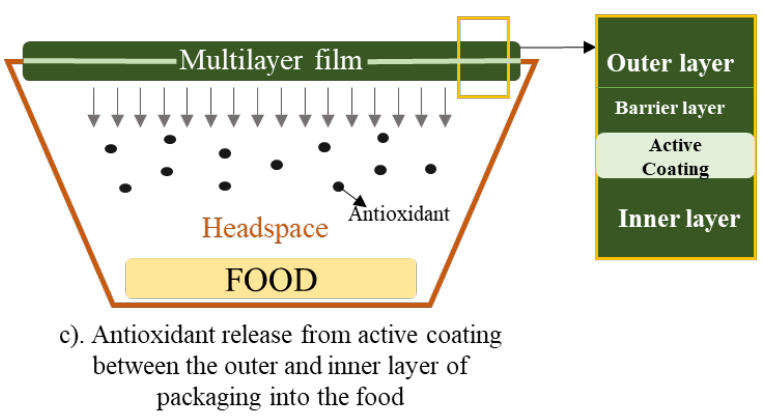



b). Antioxidant release from active coating on the inner wall of the package into the food

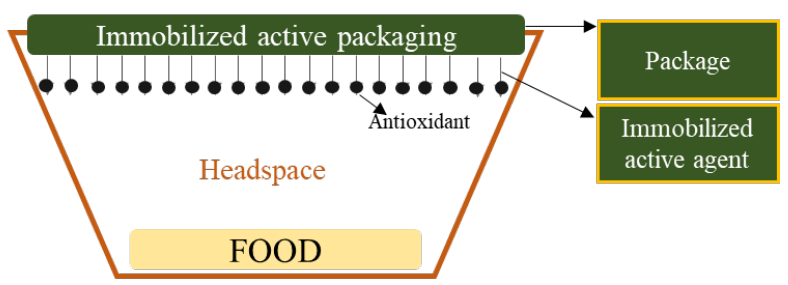

d). Antioxidant covalent bonded as immobilized active agents on the inner wall of the package

Fig. 5. Schematic representation of the application of antioxidant agents in active packaging and the migration of antioxidant agents in each system (Gaikwad et al. 2018; Nwakaudu et al. 2015).

The shelf-life of food can be improved by using active packaging. The quality and shelf life of foods influenced by oxygen in packaging. Oxygen leads to oxidation of the product or encourages aerobic microorganisms to grow, resulting in food deterioration (Yildirim et al. 2018). Foods that sensitive to oxygen would be better protected by oxygen scavenging films. This active film not only extends the shelf life of food but also maintains quality, freshness, and essential nutrients. Some potential oxygen scavenger from organic-based materials has been developed. Compared with an inorganic oxygen scavenger, organic materials such as lignin have better dispersion and compatibility with the polymeric matrix. Polymer-organic matrix is possible to 
produce optically transparent and active barrier films. Johansson et al. (2014) compared lignin derivatives such as organosolv lignin (LO), hydrolytic lignin (LH), alkali lignin (LA), and lignosulfonate (LS) as a substrate for laccase-catalyzed scavenging of oxygen in coatings and films. The oxygen-scavenging capability increased in the order $\mathrm{LO}<\mathrm{LH}<\mathrm{LA}<\mathrm{LS}$. Laccase and LS in the coated board could decrease oxygen content from $1.0 \%$ to $0.3 \%$ (Johansson et al. 2012).

\subsection{Activated carbon (AC) and supercapacitor}

Lignin has potential in the energy and chemical sector due to its chemical structure and availability. Lignin also reported being an excellent precursor for activated carbon production (Fu et al. 2013; Gao et al. 2013; Rodríguez-Correa et al. 2017; Saha et al. 2018). Activated carbon is a well-known material with high adsorptive capacity, high surface area, high reactivity, and good chemical and mechanical stability. Activated carbon not only used as an adsorbent material but also as energy storage such as supercapacitor (Hu and Hsieh 2017; Yu et al. 2016; Zeng et al. 2019). Supercapacitors can be classified into three types: hybrid capacitors, pseudocapacitors, and electric double-layer capacitors. Fig. 6 shows the main classifications of supercapacitors and are further categorized by electrode material. The electric double-layer capacitor (EDLC) is a type of storage mechanism commonly used in supercapacitors. Activated carbon (AC), graphene, and carbon nanotubes are high porous carbon materials widely used as electrode materials in the industry.

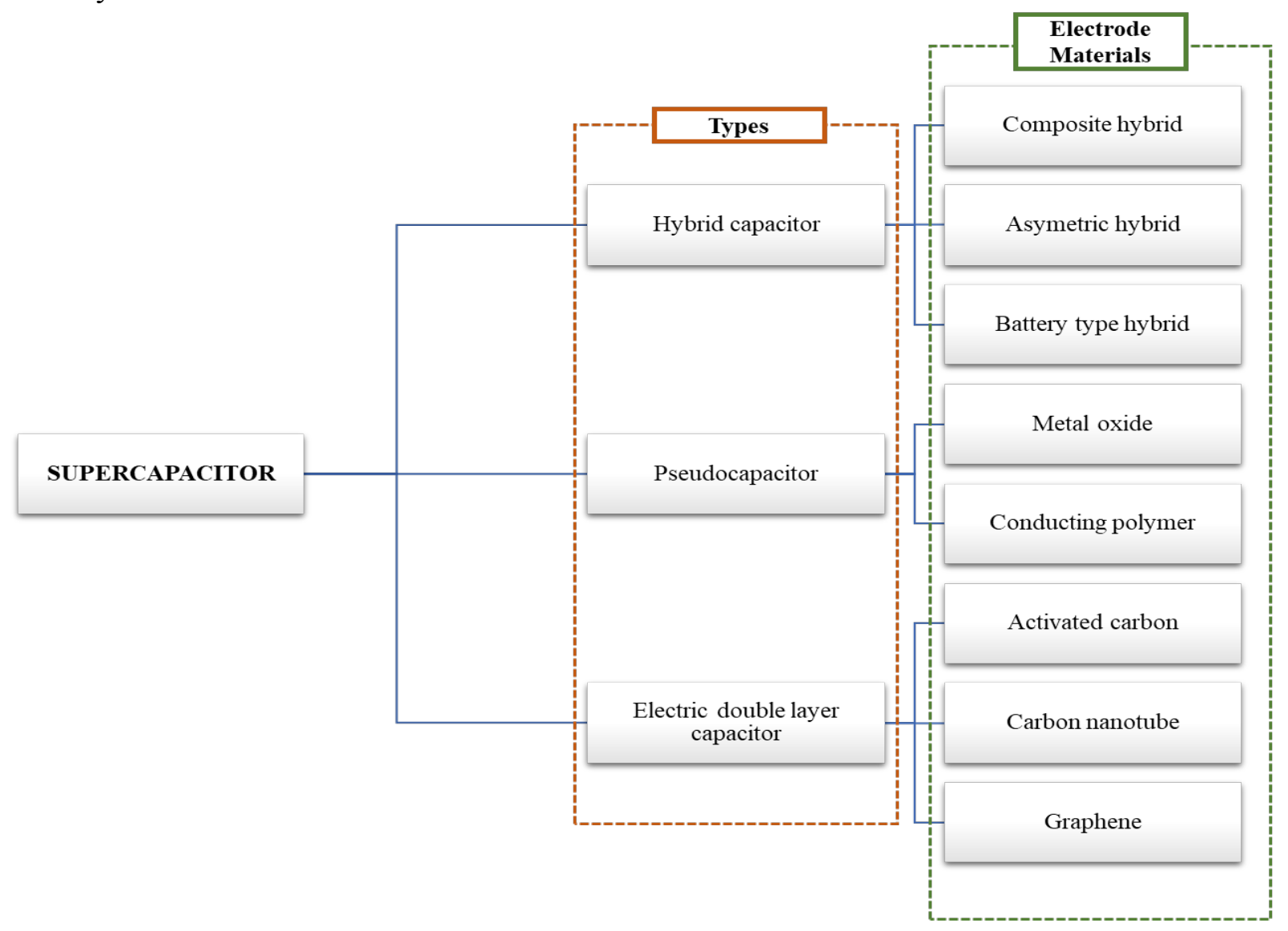

Fig. 6. Types of supercapacitors and classification based on electrode materials (González et al. 2016; Mensah-Darkwa et al. 2019). 
The pyrolysis process of lignin occurs slowly (carbonization) and over a wide temperature range. The degradation mechanisms and char formation involve initiation, propagation, and termination reactions. The solid phase structure starts from devolatilization phases (loss of weight) at temperatures higher than $500^{\circ} \mathrm{C}$. The release of $\mathrm{CO}, \mathrm{CO}_{2}, \mathrm{H}_{2}$, and $\mathrm{H}_{2} \mathrm{O}$, as well as condensable volatiles formed due to radical initiation of weaker $\mathrm{C}-\mathrm{O}$ bond in the $\beta-\mathrm{O}-4$ structure. Single- and multi-phenolic compounds start to form and then polymerized further and condensed. The formation of char residue and $\mathrm{C}-\mathrm{C}$ bonds from a combination of carbon-centered radicals is contributed by the secondary reaction between volatile components. By increasing pyrolysis temperature, the carbon content also increases. This leads to a solid matrix richer in $\mathrm{C}$ and makes the pore structure of lignin-based activated carbon stronger. The hydrogen and oxygen contents decreased because the oxygen and hydrogen-containing groups were easily fallen off at higher pyrolysis temperatures (Faravelli et al. 2010; Ma et al. 2019; Rodríguez-Correa et al. 2017).

Preparation of activated carbon from lignin has been reported by difference activation and purpose. AC from lignin was activated by $\mathrm{KOH}$ activation for $\mathrm{Ni}$ (II) adsorption (Gao et al. 2013) and benzene, toluene, and xylene (Saha et al. 2018), and steam activation for methylene blue adsorption (Albadarin et al. 2017; Fu et al. 2013). Activated carbon from lignin could be transformed into magnetic activated carbon (MAC) via hydrothermal carbonization together with formic acid. The MACs resulted in high specific pore volumes, high specific surface areas (up to $2875 \mathrm{~m}^{2} / \mathrm{g}$ ), and also have $\mathrm{CO}_{2}$ adsorption capacities up to $6.0 \mathrm{mmol} / \mathrm{g}$. Because of remarkably high ultra-micropore volumes, MAC has the potential for carbon capture and storage and gas purification processes (Hao and Bjo 2017). Rodríguez-Correa et al. (2017) compared the carbonization process between hydrothermal and pyrolysis processes on the AC properties. Activated carbon by pyrolysis has thermal stability better than the hydrothermal process. The experiment also found that the pyrolysis develops larger microporous areas than the hydrothermal process. The major reasons can be attributed to the lower amount of carbon and the higher amount of undecomposed lignin in the activated carbon by the hydrothermal process.

Supercapacitor or electrochemical capacitors has outstanding properties in energy storage conversion system. It also has a high-power density, fast charge/ discharge rate capability, and excellent cycle performance. Good performance in energy density and durability are required for carbon-based material (Borenstein et al. 2017; Faraji and Ani 2015; Poonam et al. 2019). Ligninderived activated carbon could be one of the materials that has a lower price, abundant, and environmentally friendly.

Zeng et al. (2019) reported that lignin and carbonaceous mudstone was activated with $\mathrm{HNO}_{3}$ has been successfully synthesized. As electrodes for supercapacitors, lignin and carbonaceous mudstone reveals has outstanding electrochemical behaviors and high specific capacitance (155.6 $\mathrm{F} \mathrm{g}^{-1}$ ), which is three times higher than the untreated carbon electrode. Moreover, this electrode supercapacitor presents excellent cycle behavior of 5000 cycles. Lignin derived activated carbon for supercapacitor was also activated by $\mathrm{NaOH}$ and $\mathrm{KOH}$. The obtained results exhibited excellent specific capacitance $\left(226 \mathrm{~F} \mathrm{~g} \mathrm{~g}^{-1}\right), 7.8 \mathrm{~W} \mathrm{~h} \mathrm{~kg}^{-1}$ energy density, and $47 \mathrm{~kW} \mathrm{~kg}^{-1}$ power density as well as over $92 \%$ capacitance retention after 5,000 cycles (Hu and Hsieh, 2017). 


\section{Conclusions}

Comprehensive evaluation in the structure and chemicals of lignin leads to open appropriate utilization of lignin to valuable bioproducts. Some lignin utilization for active material such as biosurfactant, antimicrobial agents, active packaging, activated carbon, and supercapacitor make this abundant material promising low-cost additive for various applications. The polymer-lignin matrix shows great potential in the future as a promising alternative to petroleum-based materials. The heterogeneity of lignin in the biomass source and processing continues to support demand in manufacturing. A more in-depth study is needed to understand the properties of natural lignin better. Modification of lignin through chemicals, physics, or biology might be required to improve lignin performance in future applications.

\section{Acknowledgments}

The authors are grateful for the support of the Research Center for Biomaterials LIPI and Integrated Laboratory of Bioproduct (iLAB) for the facilities. The authors received no specific grant from funding agencies for this work.

\section{References}

Aadil, K.R., Barapatre, A., and Jha, H. 2016a. Synthesis and Characterization of Acacia LigninGelatin Film for Its Possible Application in Food Packaging. Bioresources and Bioprocessing 3: 27. DOI: 10.1186/s40643-016-0103-y

Aadil, K.R., Prajapati, D., and Jha, H. 2016b. Improvement of Physico-Chemical and Functional Properties of Alginate Film by Acacia Lignin. Food Packaging and Shelf Life 10: 25-33. DOI: 10.1016/j.fps1.2016.09.002

Abdollahia, M., Pourmahdia, M., and Nasirib, A.R. 2018. Synthesis and Characterization of Lignosulfonate Acrylamide Graft Copolymers and Their Application in Environmentally Friendly Water-Based Drilling Fluid. Journal of Petroleum Science and Engineering 171: 484-494. DOI: 10.1016/j.petrol.2018.07.065

Afrin, T., Tsuzuki, T., Kanwar, R.K., and Wang, X. 2012. The Origin of the Antibacterial Property of Bamboo. Journal of the Textile Institute 103(8): 844-849. DOI: 10.1080/00405000.2011.614742

Albadarin, A.B., Collins, M.N., Naushad, M., Shirazian, S., Walker, G., and Mangwandi, C. 2017. Activated Lignin-Chitosan Extruded Blends for Efficient Adsorption of Methylene Blue. Chemical Engineering Journal 307: 264-272. DOI: 10.1016/j.cej.2016.08.089

Alwadani, N., and Fatehi, P. 2018. Synthetic and Lignin-Based Surfactants: Challenges and Opportunities. Carbon Resources Conversion 1(2): 126-138. DOI: 10.1016/j.crcon.2018.07.006

Alzagameem, A., Klein, S.E., Bergs, M., Do, X.T., Korte, I., Dohlen, S., Huwe, C., Kreyenschmidt, J., Kamm, B., Larkins, M., and Schulze, M. 2019. Antimicrobial Activity of Lignin and Lignin-Derived Cellulose and Chitosan Composites Against Selected Pathogenic and Spoilage Microorganisms. Polymers 11(4). DOI: 10.3390/polym 11040670 Aro, T., and Fatehi, P. 2017. Production and Application of Lignosulfonates and Sulfonated Lignin. ChemSusChem 10(9): 1861-1877. DOI: 10.1002/cssc.201700082

Borenstein, A., Hanna, O., Attias, R., Luski, S., Brousse, T., and Aurbach, D. 2017. Carbon-Based 
Composite Materials for Supercapacitor Electrodes: A Review. Journal of Materials Chemistry A 5(25): 12653-12672. DOI: 10.1039/c7ta00863e

Cai, C., Zhan, X., Zeng, M., Lou, H., Pang, Y., Yang, J., Yang, D., and Qiu, X. 2017. Using Recyclable pH-Responsive Lignin Amphoteric Surfactant to Enhance the Enzymatic Hydrolysis of Lignocelluloses. Green Chemistry 19(22): 5479-5487. DOI: $10.1039 / \mathrm{c} 7 \mathrm{gc} 02571 \mathrm{~h}$

Cazacu, G., Capraru, M., and Popa, V.I. 2013. Advances Concerning Lignin Utilization in New Materials. In Advances in Natural Polymers (pp. 255-312). Springer: Berlin.

Chan, J.M.W., Bauer, S., Sorek, H., Sreekumar, S., Wang, K., and Toste, F.D. 2013. Studies on the Vanadium-Catalyzed Nonoxidative Depolymerization of Miscanthus giganteus-Derived Lignin. ACS Catalysis 3(6): 1369-1377. DOI: 10.1021/cs400333q

Chaubey, A., Aadil, K.R., and Jha, H. 2020. Synthesis and Characterization of Lignin-Poly Lactic Acid Film as Active Food Packaging Material. Materials Technology 00(00): 1-9. DOI: 10.1080/10667857.2020.1782060

Chen, C., Zhu, M., Li, M., Fan, Y., and Sun, R.C. 2016. Epoxidation and Etherification of Alkaline Lignin to Prepare Water-Soluble Derivatives and Its Performance in Improvement of Enzymatic Hydrolysis Efficiency. Biotechnol Biofuels 9: 87. DOI: 10.1186/s13068-0160499-9

Chio, C., Sain, M., and Qin, W. 2019. Lignin Utilization: A Review of Lignin Depolymerization from Various Aspects. Renewable and Sustainable Energy Reviews 107: 232-249. DOI: 10.1016/j.rser.2019.03.008

Crouvisier-Urion, K., Farias, R.D., Arunatat, S., Griffin, D., Gerometta, M., Rocca-Smith, J. R., Weber, G., Sok, N., and Karbowiak, T. 2019. Functionalization of Chitosan with Lignin to Produce Active Materials by Waste Valorization. Green Chemistry 21(17): 4633-4641. DOI: $10.1039 / \mathrm{c} 9 \mathrm{gc} 01372 \mathrm{e}$

Diblan, S., and Kaya, S. 2018. Antimicrobial Used in Active Packaging Film. Food and Health 4(1): 63-79. DOI: 10.3153/JFHS 18007

Domenek, S., Louaifi, A., Guinault, A., and Baumberger, S. 2013. Potential of Lignins as Antioxidant Additive in Active Biodegradable Packaging Materials. Journal of Polymers and the Environment 21(3): 692-701. DOI: 10.1007/s10924-013-0570-6

Dong, X., Dong, M.I., Lu, Y., Turley, A., Jin, T., and Wu, C. 2011. Antimicrobial and Antioxidant Activities of Lignin from Residue of Corn Stover to Ethanol Production. Industrial Crops and Products 34(3): 1629-1634. DOI: 10.1016/j.indcrop.2011.06.002

Duval, A., and Lawoko, M. 2014. A Review on Lignin-Based Polymeric, Micro- and NanoStructured Materials. Reactive and Functional Polymers 85: 78-96. DOI: 10.1016/j.reactfunctpolym.2014.09.017

El-Nemr, K.F., Mohamed, H.R., Ali, M.A., Fathy, R.M., and Dhmees, A.S. 2019. Polyvinyl Alcohol/Gelatin Irradiated Blends Filled by Lignin as Green Filler for Antimicrobial Packaging Materials. International Journal of Environmental Analytical Chemistry 00(00): 1-25. DOI: 10.1080/03067319.2019.1657108

Espinoza-Acosta, J.L., Torres-Chávez, P. I., Ramírez-Wong, B., López-Saiz, C.M., \& Leyva, B.M. 2016. Antioxidant, Antimicrobial, and Antimutagenic Properties of Technical Lignins and Their Applications. BioResoures 11(2): 5452-5481.

Fakruddin, M. 2012. Biosurfactant: Production and Application. Journal of Petroleum \& Environmental Biotechnology 03(04). DOI: 10.4172/2157-7463.1000124 
Faraji, S., and Ani, F.N. (2015). The Development Supercapacitor from Activated Carbon by Electroless Plating - A Review. Renewable and Sustainable Energy Reviews 42: 823-834. DOI: 10.1016/j.rser.2014.10.068

Faravelli, T., Frassoldati, A., Migliavacca, G., and Ranzi, E. 2010. Detailed Kinetic Modeling of the Thermal Degradation of Lignins. Biomass and Bioenergy 34(3): 290-301. DOI: 10.1016/j.biombioe.2009.10.018

Fatriasari, W., Hamzah, F.N., Pratomo, B.I. , Fajriutami, T., Ermawar, R.A. , Falah, F., Ghozali, M., Iswanto, A.H., Hermiati, E., and Winarni, I. 2020. Optimizing the Synthesis of Lignin Derivatives from Acacia mangium to Improve the Enzymatic Hydrolysis of Kraft Pulp Sorghum Bagasse. Int $J$ Renew Energy Dev (IJRED) 9(2): 227-235. DOI: 10.14710/ijred.9.2.227-235

Fatriasari, W., Nugroho Adi, D.T., Laksana, R.P.B., Fajriutami, T., Raniya, R., Ghozali, M., and Hermiati, E. 2018. The Effect of Amphipilic Lignin Derivatives Addition on Enzymatic Hydrolysis Performance of Kraft Pulp from Sorghum Bagasse. in IOP Conference Series: Earth Environ Sci. DOI: 10.1088/1755-1315/141/1/012005

Fatriasari, W., Supriyanto, and Iswanto, A.H. 2015. The Kraft Pulp And Paper Properties of Sweet Sorghum Bagasse (Sorghum bicolor L Moench). J Eng Tech Sci 47(2): 149-159. DOI: 10.5614/j.eng.technol.sci.2015.47.2.4

Faustino, H., Gil, N., Baptista, C., and Duarte, A.P. 2010. Antioxidant Activity of Lignin Phenolic Compounds Extracted from Kraft and Sulphite Black Liquors. Molecules 9308-9322. DOI: 10.3390/molecules 15129308

Fu, K., Yue, Q., Gao, B., Sun, Y., and Zhu, L. 2013. Preparation, Characterization and Application of Lignin-Based Activated Carbon from Black Liquor Lignin by Steam Activation. Chemical Engineering Journal 228: 1074-1082. DOI: 10.1016/j.cej.2013.05.028

Gabov, K., Oja, T., Deguchi, T., Fallarero, A., and Fardim, P. 2016. Preparation, Characterization and Antimicrobial Application of Hybrid Cellulose-Lignin Beads. Cellulose 24(2): 641-658. DOI: 10.1007/s10570-016-1172-y

Gaikwad, K.K., Singh, S., and Lee, Y. S. (2018). Oxygen Scavenging Films in Food Packaging. Environmental Chemistry Letters 16(2): 523-538. DOI: 10.1007/s10311-018-0705-Z

Gao, Y., Yue, Q., Gao, B., Sun, Y., Wang, W., Li, Q., and Wang, Y. 2013. Preparation of High Surface Area-Activated Carbon from Lignin of Papermaking Black Liquor by $\mathrm{KOH}$ Activation for Ni (II) Adsorption. Chemical Engineering Journal 217: 345-353. DOI: 10.1016/j.cej.2012.09.038

Gargulak, J.D., and Lebo, S.E. 1999. Commercial Use of Lignin-Based Materials. In Lignin: Historical, Biological, and Materials Perspectives (pp. 304-320). ACS: Washington.

González, A., Goikolea, E., Barrena, J.A., and Mysyk, R. 2016. Review on Supercapacitors: Technologies and Materials. Renewable and Sustainable Energy Reviews 58: 1189-1206. DOI: $10.1016 /$ j.rser.2015.12.249

Gordobil, O., Egüés, I., Llano-Ponte, R., and Labidi, J. 2014. Physicochemical Properties of PLA Lignin Blends. Polymer Degradation and Stability 108. DOI: 10.1016/j.polymdegradstab.2014.01.002

Gordobil, O., Herrera, R., Yahyaoui, M., İlk, S., Kaya, M., and Labidi, J. 2018. Potential Use of Kraft and Organosolv Lignins as a Natural Additive for Healthcare Products. RSC Advances 8(43): 24525-24533. DOI: $10.1039 / \mathrm{c} 8 \mathrm{ra} 02255 \mathrm{k}$

Guo, Y., Tian, D., Shen, F., Yang, G., Long, L., He, J., Song, C., Zhang, J., Zhu, Y., Huang, C., 
and Deng, S. 2019. Transparent Cellulose/Technical Lignin Composite Films for Advanced Packaging. Polymers 11(9): 1-11. DOI: 10.3390/polym11091455

Hao, W., and Bjo, F. 2017. High-Performance Magnetic Activated Carbon from Solid Waste from Lignin Conversion Processes. 1. Their Use as Adsorbents for $\mathrm{CO}_{2}$. ACS Sustainable Chem. Eng. 5(4): 3087-3095. DOI: 10.1021/acssuschemeng.6b02795

Hermiati, E., Risanto, L., Lubis, M.A.R., Laksana, R.P.B., Dewi, A.R. 2017. Chemical Characterization of Lignin from Kraft Pulping Black Liquor of Acacia mangium. In: Int Symp on Appl Chem (ISAC). AIP Conf. Proc. 020001-020007. DOI:10.1063/1.4973132

$\mathrm{Hu}$, S., and Hsieh, Y.L. 2017. Lignin Derived Activated Carbon Particulates as an Electric Supercapacitor: Carbonization and Activation on Porous Structures and Microstructures. RSC Advances 7(48): 30459-30468. DOI: 10.1039/c7ra00103g

Huang, C., Ma, J., Zhang, W., Huang, G., and Yong, Q. 2018. Preparation of Lignosulfonates from Biorefinery Lignins by Sulfomethylation and Their Application as a Water Reducer for Concrete. Polymers (Basel) 10(8). DOI: 10.3390/polym10080841

Huang, J., Fu, S., and Gan, L. 2019. Chapter 4 - Lignin Chemicals and Their Applications. In Huang, J., Fu, S., and Gan, L. (Eds.), Lignin Chemistry and Applications (pp. 79-134). Amsterdam, The Netherlands: Elsevier.

Jiao, Y., Xu, Z., Qiao, W., and Li, Z. 2007. Research Interfacial Properties of the Novel Lignosulfonates. Energy Sources, Part A: Recovery, Utilization, and Environmental Effects 29(15): 1425-1432. DOI: 10.1080/00908310600710699

Johansson, K., Gillgren, T., Winestrand, S., Järnström, L., and Jönsson, L. J. 2014. Comparison of Lignin Derivatives as Substrates for Laccase-Catalyzed Scavenging of Oxygen in Coatings and Films. 1-10.

Johansson, K., Winestrand, S., Johansson, C., Järnström, L., and Jönsson, L. J. 2012. OxygenScavenging Coatings and Films Based on Lignosulfonates and Laccase. Journal of Biotechnology 161(1): 14-18. DOI: 10.1016/j.jbiotec.2012.06.004

Jung, H.G., and Fahey, G.C. 1983. Nutritional Implications of Phenolic Monomers and Lignin: A Review. Journal of Animal Science 57(1): 206-219.

Kai, D., Tan, M.J., Chee, P.L., Chua, Y.K., Yap, Y.L., and Loh, X.J. 2016. Towards Lignin-Based Functional Materials in a Sustainable World. Green Chemistry 18(5): 1175-1200. DOI: $10.1039 / \mathrm{c} 5 \mathrm{gc0} 62616 \mathrm{~d}$

Kelley, J.R. 1983. U.S Patent No. US4322301A. Georgia Pacific Corp.

Kinyanjui, T., Artz, W.E., and Mahungu, S. 2003. EMULSIFIERS: Organic Emulsifiers. In Benjamin Caballero (Ed.), Encyclopedia of Food Sciences and Nutrition (Second Edition) (pp. 2070-2077). Oxford: Academic Press.

Klein, A., Rumpf, K., Kreyenschmidt, and Schulze. 2019. Antimicrobial Activity of LigninDerived Polyurethane Coatings Prepared from Unmodified and Demethylated Lignins. Coatings 9(8). DOI: 10.3390/coatings9080494

Konduri, M.K.R., and Fatehi, P. 2018. Designing Anionic Lignin Based Dispersant for Kaolin Suspensions. Colloids and Surfaces A: Physicochemical and Engineering Aspects 538: 639650. DOI: 10.1016/j.colsurfa.2017.11.011

Li, H., and Peng, L. 2015. Antimicrobial and Antioxidant Surface Modification of Cellulose Fibers using Layer-by-Layer Deposition of Chitosan and Lignosulfonates. Carbohydrate Polymers, 124: 35-42. DOI: 10.1016/j.carbpol.2015.01.071

Liu, Z., Lu, X., An, L., and Xu, C. 2016. A Novel Cationic Lignin-Amine Emulsifier with High 
Performance Reinforced via Phenolation and Mannich Reactions. BioResources 11(3): 6438-6451.

Liu, Z., Zhao, L., Cao, S., Wang, S., and Li, P. 2013. Preparation and Evaluation of a Novel Cationic Amphiphilic Lignin Derivative with High Surface Activity. BioResources 8(4): 6111-6120.

Lou, H., He, X., Cai, C., Lan, T., Pang, Y., Zhou, H., and Qiu, X. 2019. Enhancement and Mechanism of a Lignin Amphoteric Surfactant on the Production of Cellulosic Ethanol from a High-Solid Corncob Residue. J Agric Food Chem 67(22): 6248-6256. DOI: 10.1021/acs.jafc.9b01208

Ma, Z., Yang, Y., Wu, Y., Xu, J., Peng, H., Liu, X., Zhang, W., and Wang, S. 2019. In-Depth Comparison of the Physicochemical Characteristics of Bio-char derived from Biomass Pseudo Components: Hemicellulose, Cellulose, and Lignin. Journal of Analytical and Applied Pyrolysis 140: 195-204. DOI: 10.1016/j.jaap.2019.03.015

Ma'ruf, A., Pramudono, B., and Aryanti, N. 2018. Synthesis of Natural Surfactant of Sodium Lignosulfonate from Rice Husk Lignin by Ultrasound Assisted - Sulfonation. Key Engineering Materials 775: 20-25. DOI: 10.4028/www.scientific.net/KEM.775.20

Market and Market (MNM). 2020. Bioplastics \& Biopolymers Market by Type (NonBiodegradable/Bio-Based, Biodegradable), End-Use Industry (Packaging, Consumer Goods, Automotive \& Transportation, Textiles, Agriculture \& Horticulture), Region Global Forecast to 2025. <https://www.marketsandmarkets.com/MarketReports/biopolymers-bioplastics-market-88795240.html>

Mensah-Darkwa, K., Zequine, C., Kahol, P.K., and Gupta, R.K. (2019). Supercapacitor Energy Storage Device using Biowastes: A Sustainable Approach to Green Energy. Sustainability, 11(2). DOI: $10.3390 /$ su1 1020414

Minet, J., Cayla, A., and Campagne, C. 2019. Lignin as Sustainable Antimicrobial Fillers to Develop PET Multifilaments by Melting Process. In Bio-Based Polymers: IntechOpen.

Moreno, A., and Sipponen, M.H. 2020. Lignin-Based Smart Materials: A Roadmap to Processing and Synthesis for Current and Future Applications. Materials Horizons 7(9): 2237-2257. DOI: $10.1039 / \mathrm{d} 0 \mathrm{mh} 00798 \mathrm{f}$

Mushtaq, M., Tan, I.M., and Sagir, M. 2014. New Surfactants for EOR Applications: Effect of Chain Length on Performance. AIP Conference Proceedings (1621), 742-748. DOI: $10.1063 / 1.4898550$

Nakagawa-Izumi, A., H'ng, Y.Y., Mulyantara, L.T, Maryana, R., Do, V.T., and Ohi, H. 2017. Characterization of Syringyl and Guaiacyl Lignins in Thermomechanical Pulp from Oil Palm Empty Fruit Bunch by Pyrolysis-Gas Chromatography-Mass Spectrometry using Ion Intensity Calibration. Industrial Crops and Products 95: 615-620. DOI: 10.1016/j.indcrop.2016.11.030

Norgren, M., and Edlund, H. 2014. Lignin: Recent Advances and Emerging Applications. Current Opinion in Colloid and Interface Science 19(5): 409-416. DOI: 10.1016/j.cocis.2014.08.004 Nwakaudu, A.A., Nwakaudu, M.S., Owuamanam, C.I., and Iheaturu, N.C. 2015. The Use of Natural Antioxidant Active Polymer Packaging Films for Food Preservation. Applied Signals Reports 2(4): 38-50.

Pan, X., Kadla, J.F., Ehara, K., Gilkes, N., and Saddler, J.N. 2006. Organosolv Ethanol Lignin from Hybrid Poplar as a Radical Scavenger: Relationship between Lignin Structure, Extraction Conditions, and Antioxidant Activity. Journal of Agricultural and Food 
Chemistry 54(16): 5806-5813. DOI: 10.1021/jf0605392

Peng, R., Pang, Y., Qiu, X., Qian, Y., and Zhou, M. 2020. Synthesis of anti-Photolysis LigninBased Dispersant and Its Application in Pesticide Suspension Concentrate. RSC Advances 10(23): 13830-13837. DOI: 10.1039/c9ra10626j

Poonam, S.K., Arora, A., and Tripathi, S.K. 2019. Review of Supercapacitors: Materials and Devices. Journal of Energy Storage 801-825. DOI: 10.1016/j.est.2019.01.010

Qing, A.I., Fang, G.Z. Zhao, Y.F., Wang, C.H., and Ren, S.X. 2009. Synthesis and Characterization of Diethanolamine-based Lignin Nonionic Surfactant. Chemistry and Industry of Forest Products 29(6): 52-56.

Rempe, C.S., Burris, K.P., Lenaghan, S.C., and Stewart, C.N. 2017. The Potential of Systems Biology to Discover Antibacterial Mechanisms of Plant Phenolics. Frontiers in Microbiology 8: 422. DOI: 10.3389/fmicb.2017.00422

Riaz, S., and Ashraf, M. 2020. Recent Advances in Development of Antimicrobial Textiles. In M. Shahid and R. Adivarekar (Eds.), Advances in Functional Finishing of Textiles (pp. 129168). Singapore: Springer.

Rodríguez-Correa, C., Stollovsky, M., Hehr, T., Rauscher, Y., Rolli, B., and Kruse, A. 2017. Influence of the Carbonization Process on Activated Carbon Properties from Lignin and Lignin-Rich Biomasses. ACS Sustainable Chemistry and Engineering 5(9): 8222-8233. DOI: 10.1021/acssuschemeng.7b01895

Saha, D., Mirando, N., and Levchenko, A. 2018. Liquid and Vapor Phase Adsorption of BTX in Lignin Derived Activated Carbon: Equilibrium and Kinetics Study. Journal of Cleaner Production 182: 372-378. DOI: 10.1016/j.jclepro.2018.02.076

Sinisi, V., Pelagatti, P., Carcelli, M., Migliori, A., Mantovani, L., Righi, L., Leonardi, G., Pietarinen, S., Hubsch, C., and Rogolino, D. 2018. A Green Approach to Copper-Containing Pesticides: Antimicrobial and Antifungal Activity of Brochantite Supported on Lignin for the Development of Biobased Plant Protection Products. ACS Sustainable Chemistry \& Engineering 7(3): 3213-3221. DOI: 10.1021/acssuschemeng.8b05135

Spiridon, I., Leluk, K., Resmerita, A.M., and Darie, R.N. 2015. Evaluation of PLA-Lignin Bioplastics Properties Before and After Accelerated Weathering. Composites Part B: Engineering 69: 342-349. DOI: 10.1016/j.compositesb.2014.10.006

Sriroth, K., and Sunthornvarabhas, J. 2018. Lignin from Sugar Process as Natural Antimicrobial Agent. Biochemistry and Pharmacology: Open Access 07(01). DOI: 10.4172/21670501.1000239

Sunthornvarabhas, J., Liengprayoon, S., Lerksamran, T., Buratcharin, C., Suwonsichon, T.I, Vanichsriratana, W., and Sriroth, K. 2018. Utilization of Lignin Extracts from Sugarcane Bagasse as Bio-based Antimicrobial Fabrics. Sugar Tech 21(2): 355-363. DOI: 10.1007/s12355-018-0683-2

Sunthornvarabhas, J., Liengprayoon, S., and Suwonsichon, T. 2017. Antimicrobial Kinetic Activities of Lignin from Sugarcane Bagasse for Textile Product. Industrial Crops and Products 109: 857-861. DOI: 10.1016/j.indcrop.2017.09.059

Thakur, V.K., Thakur, M.K, Raghavan, P., and Kessler, M.R. 2014. Progress in Green Polymer Composites from Lignin for Multifunctional Applications: A Review. ACS Sustainable Chemistry and Engineering 2(5): 1072-1092. DOI: $10.1021 / \mathrm{sc} 500087 \mathrm{z}$

Tian, J., Ren, S., Fang, G., Ma, Y., and Ai, Q. 2014. Preparation and Performance of DimethylAcetoxy(2-Carboxymethyl Ether)-Lignin Ammonium Chloride Amphoteric Surfactant. 
BioResources 9(4): 6290-6303.

Uraki, Y., Ishikawa, N., Nishida, M., and Sano, Y. 2001. Preparation of Amphipilic Lignin Derivative as Cellulose Stabilizer. J Wood Sci 47: 301-307. DOI: 10.1007/BF00766717

Vinardell, M.P., Ugartondo, V., and Mitjans, M. 2008. Potential Applications of Antioxidant Lignins from Different Sources. Industrial Crops and Products 27(2), 220-223. DOI: 10.1016/j.indcrop.2007.07.011

Vostrejs, P., Adamcová, D., Vaverková, M. D., Enev, V., Kalina, M., Machovsky, M., Šourková, M., Marova, I., and Kovalcik, A. 2020. Active Biodegradable Packaging Films Modified with Grape Seeds Lignin. RSC Advances 10(49): 29202-29213. DOI: 10.1039/d0ra04074f

Winowiski, T. S., and Zajakowski, V. L. 2000. US Patent No. US6113974A.

Wood, L. 2019. Global Agricultural Surfactants Market 2019-2024: \$1.85 Billion Opportunity in

Production of Sustainable Bio-Based Surfactant Products. Research and Markets.

$\mathrm{Xu}, \mathrm{C}$., and Ferdosian, F. 2017. Utilization of Lignosulfonate as Dispersants or Surfactants. In Conversion of Lignin into Bio-Based Chemicals and Materials (pp. 81-90). Springer: Germany.

Xu, J., Zhang, Y., Chen, H., Wang, P., Xie, Z., Yao, Y., Yan, Y., and Zhang, J. 2013. Effect of Surfactant Headgroups on the Oil/Water Interface: An Interfacial Tension Measurement and Simulation Study. Journal of Molecular Structure 1052: 50-56. DOI: 10.1016/j.molstruc.2013.07.049

Yamashita, Y., and Sakamoto, K. 2016. Hydrophilic-Lipophilic Balance (HLB): Classical Indexation and Novel Indexation of Surfactant. In Hiroyuki Ohshima (Ed.), Encyclopedia of Biocolloid and Biointerface Sci. (pp. 570-574). New York: Wiley and Sons.

Yang, W., Fortunati, E., Dominici, F., Giovanale, G., Mazzaglia, A., Balestra, G. M., Kenny, J. M., and Puglia, D. 2016a. Synergic Effect of Cellulose and Lignin Nanostructures in PLA Based Systems for Food Antibacterial Packaging. European Polymer Journal 79: 1-12. DOI: 10.1016/j.eurpolymj.2016.04.003

Yang, W., Owczarek, J.S., Fortunati, E., Kozanecki, M., Mazzaglia, A., Balestra, G.M., Kenny, J.M., Torre, L., and Puglia, D. 2016b. Antioxidant and Antibacterial Lignin Nanoparticles in Polyvinyl Alcohol/Chitosan Films for Active Packaging. Industrial Crops and Products 94: 800-811. DOI: 10.1016/j.indcrop.2016.09.061

Yang, W., Weng, Y., Puglia, D., Qi, G., Dong, W., Kenny, J. M., and Ma, P. 2020. Poly(lactic acid)/Lignin Films with Enhanced Toughness and Anti-Oxidation Performance for Active Food Packaging. International Journal of Biological Macromolecules 144: 102-110. DOI: 10.1016/j.ijbiomac.2019.12.085

Yildirim, S., Röcker, B., Pettersen, M. K., Nilsen-Nygaard, J., Ayhan, Z., Rutkaite, R., Radusin, T., Suminska, P., Marcos, B., and Coma, V. 2018. Active Packaging Applications for Food. Comprehensive Reviews in Food Science and Food Safety 17(1): 165-199. DOI: 10.1111/1541-4337.12322

Yu, B., Chang, Z., and Wang, C. 2016. The Key Pre-Pyrolysis in Lignin-Based Activated Carbon Preparation for High Performance Supercapacitors. Materials Chemistry and Physics 181: 187-193. DOI: 10.1016/j.matchemphys.2016.06.048

Yoo, C.G., Dumitrache, A., Muchero, W., Natzke, J., Akinosho, H., Li, M., Sykes, R.W., Brown, S.D., Davison, B., Tuskan, G.A., Pu, Y., and Ragauskas, A.J. 2017. Significance of Lignin $\mathrm{S} / \mathrm{G}$ Ratio in Biomass Recalcitrance of Populus trichocarpa Variants for Bioethanol Production. ACS Sustainable Chemistry and Engineering 6(2): 2162-2168. DOI: 


\subsection{1/acssuschemeng.7b03586}

Zadeh, E.M., O'Keefe, S.F., and Kim, Y.T. 2018. Utilization of Lignin in Biopolymeric Packaging Films [Research-article]. ACS Omega 3(7): 7388-7398. DOI: 10.1021/acsomega.7b01341

Zadeh, M.E., O’Keefe, S.F., and Kim, Y.T. 2019. Lignin-Based Biopolymeric Active Packaging System for Oil Products. Journal of Food Science 84(6): 1420-1426. DOI: 10.1111/17503841.14632

Zeng, L., Lou, X., Zhang, J., Wu, C., Liu, J., and Jia, C. 2019. Carbonaceous Mudstone and LigninDerived Activated Carbon and Its Application for Supercapacitor Electrode. Surface and Coatings Technology 357: 580-586. DOI: 10.1016/j.surfcoat.2018.10.041

Zhang, H., Bai, Y., Zhou, W., and Chen, F. 2017a. Color Reduction of Sulfonated Eucalyptus Kraft Lignin. Int J Biol Macromol 97: 201-208. DOI: 10.1016/j.ijbiomac.2017.01.031

Zhang, Ji., Ge, Y., Qin, L., Huang, W., and Li, Z. 2017b. Synthesis of a Lignin-Based Surfactant through Amination, Sulfonation, and Acylation. Journal of Dispersion Science and Technology 39(8): 1140-1143. DOI: 10.1080/01932691.2017.1385478

Zhang, Z., Harrison, M.D., Rackemann, D.W., Doherty, W.O.S., and O'Hara, I.M. 2016. Organosolv Pretreatment of Plant Biomass for Enhanced Enzymatic Saccharification. Green Chemistry 18(2): 360-381. DOI: 10.1039/c5gc02034d

Zhao, X., Cheng, K., and Liu, D. 2009. Organosolv Pretreatment of Lignocellulosic Biomass for Enzymatic Hydrolysis. Appl Microbiol Biotechnol 82(5): 815-827. DOI: 10.1007/s00253009-1883-1

Zhou, M., Wang, W. Yang, D., and Qiu, X. 2015. Preparation of a New Lignin-Based Anionic/Cationic Surfactant and Its Solution Behaviour. RSC Advances 5(4): 2441-2448. DOI: $10.1039 / \mathrm{c} 4 \mathrm{ra10524a}$

Zhu, Y., Li, Z., and Chen, J. 2019. Applications of Lignin-Derived Catalysts for Green Synthesis. Green Energy and Environment 4(3): 210-244. DOI: 10.1016/j.gee.2019.01.003 